\title{
REFUGIADOS, MIGRANTES E RESISTÊNCIAS \\ UMA ENTREVISTA COM A PROFESSORA CAROLINA MOULIN AGUIAR
}

(UFMG)

A Revista escrita pediu para a professora Carolina Moulin Aguiar, professora da UFMG e antiga coordenadora da graduação do Instituto de Relações Internacionais da PUC-Rio, responder a cinco perguntas, cujas respostas foram então transcritas. As questões foram elaboradas pelo corpo editorial do presente número e visavam procurar interseções entre o campo de estudo da professora e indagações suscitadas pelos temas desta edição. Agradecemos mais uma vez a disponibilidade e a participação da professora.

Em sua dissertação, você trabalhou com o "processo de construção social do Refugiado" em dois momentos do século XX: de 1945 a 1954 e no pós-Guerra Fria. Como você compara as duas primeiras décadas do século XXI a esses dois períodos históricos no que diz respeito a (i)migrações e refugiados? Como as populações mudaram? E houve alguma mudança significativa de legislações para que países pudessem receber esse novo fluxo migratório?

Na minha dissertação, o que ficou muito evidente foi que, até a II Guerra Mundial, o princípio que norteou a proteção a refugiados na primeira metade do século $\mathrm{XX}$ era sobretudo o princípio do pertencimento nacional. Todo regime de proteção que foi criado nesse período se voltava à proteção de determinados grupos de refugiados em função do seu vínculo a determinado país e nacionalidade. Com o fim da II Guerra Mundial, temos um processo de inflexão para uma certa universalização não só do refúgio, mas também dos princípios de proteção à pessoa humana, encabeçados pela Declaração Universal de Direitos Humanos, numa série de tratados - dentre eles, a Convenção de 1951 sobre o Estatuto dos Refugiados. O princípio que passa a ser fundamental é o da territorialidade, ou seja, a proteção está aberta a qualquer pessoa que demonstra perseguição, mas que tenha cruzado uma fronteira internacional. A mobilidade internacional passa a ser um requisito para a obtenção do refúgio, independentemente das razões que levam a essa mobilidade, desde que enquadradas nos princípios gerais estaecidos no Artigo I da Convenção, como a perseguição política por origem nacional, por critérios étnicoreligiosos, por pertencimento a grupo social etc. É uma inflexão importante, pois, até então, só se conseguia garantir a proteção a refugiados se fossem russos, alemães... Toda 
normativa internacional era voltada para esse requisito, e agora isso foi expandido para incluir todas aquelas pessoas que se veem forçadas a sair de seus lugares de origem ou residência habitual e vão para outros países.

O que começamos a ver no pós-Guerra Fria e no século XXI, com o ápice desse processo e as dificuldades daí derivadas? A primeira questão é a da proliferação de categorias. É a incapacidade de usar a perseguição individual como um parâmetro mais geral para obtenção da proteção. Ou seja, vamos pensar no caso de Ruanda, em que havia milhares de pessoas chegando à fronteira com a Tanzânia em um único dia. Isso tornava impossível fazer uma avaliação da perseguição caso a caso. Começamos a ver fluxos de pessoas que chamamos de massivos que põem o sistema em colapso. Começamos a ver o chamado "refugiado prima facie", que é aquele reconhecido por vir de um contexto de crise política, de guerra civil etc.

Nesse mesmo processo, surgem outros motivos que levam ao deslocamento forçado que não a perseguição: colapso estatal, incapacidade do Estado de prover proteção - situações em que as pessoas são forçadas a serem deslocadas por políticas do Estado às vezes voltadas para determinados grupos, como a perseguição a grupos LGBT, perseguição por etnia -, um recrudescimento de nacionalismos, questões ambientais ou até projetos às vezes governamentais de forçar a população a sair de determinada região. É uma série de outros fatores que não estavam previstos na Convenção e que se apresentam para os Estados quando esses fluxos chegam a seus países. Eu chamava de um conjunto de quase refugiados. A eles, se juntam aqueles que se veem deslocados dentro de seus próprios países. Houve uma explosão nos últimos 30 anos do número de populações internamente deslocadas; na realidade, elas não conseguem ou não desejam sair de seu país de origem, mas se veem forçosamente deslocadas do seu território de residência.

Países como a Colômbia têm um número enorme de pessoas que conseguiram sair e que permaneceram e que precisam de algum tipo de proteção internacional. Por não terem saído do país, se veem num certo limbo jurídico, já que o regime de proteção a refugiados não se volta para essas populações. A ONU tenta dar um conjunto de respostas, e existe um conjunto de diretrizes inauguradas em 1948 com relação a populações internamente deslocadas. Em resumo, a segunda questão é a incapacidade das pessoas de cruzarem uma fronteira internacional. 
Uma terceira dimensão que vale a pena demonstrar e que se mostrou mais acirrada no século XXI diz respeito à incapacidade de fazer uma distinção clara entre os motivos pelos quais as pessoas se movem internacionalmente. Muitas das narrativas de migrantes e também dos próprios refugiados começam a se confundir. São projetos migratórios complexos, envolvendo violência, pobreza, fatores econômicos e fatores estruturais dos lugares de origem, sendo muito difícil delimitar conceitualmente dentro de qual dessas chaves essas pessoas estariam enquadradas. Isso faz emergir como resposta, particularmente nos países do norte, de recepção, e cada vez mais nos países do sul que têm recebido esses novos fluxos, um processo que chamamos de perda da relevância da distinção entre refugiado e migrante, que eram duas categorias que estruturaram a mobilidade internacional no século XX. Em vez disso, a distinção fica cada vez mais centrada na legalidade ou ilegalidade desse movimento. Tem mais a ver com como as pessoas chegam ao país de destino e menos a ver com a natureza e a dinâmica desses fluxos, o que coloca essas pessoas, obviamente, numa situação de profunda precariedade, normalmente em situações de discricionariedade burocrática, num certo limbo judicial. São questões que estão pululando no noticiário quase que diuturnamente: detenções arbitrárias, deportações sumárias e um conjunto de políticas de contenção que ocorrem à margem, muitas vezes, das normativas legais estabelecidas.

Esses são grandes desafios que o século XXI coloca, mas eles não são novos. São derivados dos processos de transformação dinâmica da mobilidade internacional de desde o século XX. Por exemplo, políticas de controle extraterritorial, de contenção desses fluxos em terceiros países, geralmente países fronteiriços, como na Europa, são uma experiência que já vem sendo feita pelo menos desde o final da década de 1980. O mesmo se vê nos Estados Unidos. Com a crise de 1980 de vários países centro-americanos, vimos políticas muito similares às que encontramos hoje com relação a esses fluxos do Triângulo Norte. São processos que vêm se agudizando; não são novos, mas são indicativos das transformações mais sistêmicas das respostas estatais, do tipo de cooperação que os Estados têm produzido no campo da mobilidade, e do ponto de vista da transformação dos próprios fluxos e da dinâmica desses fluxos, obviamente tendo em vista os processos de globalização, que envolvem também uma maior facilidade na circulação de bens e serviços e de pessoas. 


\section{Você foi a coordenadora da graduação do Instituto de Relações Internacionais (IRI) da PUC-Rio. A situação contemporânea dos refugiados alterou a composição do curso? Em caso positivo, de que forma? Em caso negativo, você vê uma demanda de alunos e profissionais do ramo para que o tema figure mais em disciplinas da graduação?}

No âmbito do impacto desse tema na composição do curso de Relações Internacionais da PUC-Rio, eu diria que, certamente, nos últimos 10 anos, identificamos facilmente uma tendência a um maior interesse do corpo discente pelas temáticas que envolvem migração e fronteiras. Não foi só do ponto de vista acadêmico, de uma reflexão digamos mais científica sobre esses processos e dinâmicas, mas também do ponto de vista de uma formação profissional mais adequada. Assim, esses discentes vão poder se tornar profissionais do terceiro setor, de organismos internacionais, think tanks e governos que vão atuar especificamente em áreas não só diretamente atreladas ao tema da migração e do refúgio, mas muitas vezes em áreas conexas que têm impacto sobre o tema da migração e sobre as quais o tema da migração impacta. Por exemplo, temos alunos que foram trabalhar em organismos não governamentais na área de saúde. O tema da saúde obviamente tem um olhar muito específico com relação à circulação de pessoas: as questões sanitárias e uma atenção mais específica dos sistemas de saúde a populações migrantes e refugiados. Pessoas que vão trabalhar na área de políticas educacionais e de assistência social. Todas essas áreas que, historicamente, foram, digamos, reserva de um conjunto de profissionais se veem hoje com essa demanda do internacionalista, de uma pessoa que seja capaz de entender esse processo a partir de uma perspectiva mais global, mais geral.

Temos vários ex-alunos que têm trabalhado e atuado nessa temática no Brasil e no exterior, em organismos governamentais, nacionais, internacionais, e sobretudo no terceiro setor, em ONGs de base local, mas também com perfil transnacional.

Sua linha de atuação refere-se ao estudo das Fronteiras políticas e da mobilidade humana. De que forma você relaciona essas duas questões?

O tema da fronteira é obviamente central às dinâmicas de mobilidade global. A possibilidade de acesso a um território estrangeiro é uma das características fundamentais 
para a possibilidade dos projetos migratórios. Parte das questões com as quais lidamos hoje nos campos político, social e econômico diz respeito justamente ao impacto de políticas de controle e gestão fronteiriças sobre esses fluxos e as consequências desumanas que essas políticas têm produzido no campo da proteção e da possibilidade de acesso aos instrumentos internacionais voltados à mobilidade, dentre os quais está a condição refugiada. A relação entre as fronteiras e a mobilidade é umbilical. É impossível falar de mobilidade sem falar de fronteira, e não dá para falar de fronteira sem pensar nesse espaço, historicamente, como um espaço de circulação, de troca. Ele tensiona uma série de pressupostos organizadores da vida política internacional, como a noção do Estado nacional, que depende da existência de marcadores espaciais e geográficos, da burocracia estatal voltada à gestão da mobilidade, obviamente muito centrada na criação de redes de controle cada vez mais transnacionais, envolvendo não só Estados, como atores privados (p. ex., as empresas transportadoras). Os órgãos de gestão policial também se voltam cada vez mais ao tema do fluxo migratório.

Entendo que pensar na mobilidade necessariamente implica olhar para a centralidade das fronteiras políticas como dinâmicas constitutivas da ordem internacional contemporânea, mas que também abrem espaço para sua transformação, sua reconstituição. Parte dos processos de globalização diz respeito justamente a uma certa fluidez e a uma incapacidade crescente dos Estados nacionais de lidarem com o problema da fronteira.

\section{Com base em seus estudos, como os refugiados têm resistido às políticas de extrema direita que têm vetado os fluxos migratórios oriundos dos países em desenvolvimento e/ou em guerra?}

A primeira forma de resistência é a própria persistência do fenômeno da mobilidade. Ou seja, a despeito do número crescente de mortes e das necropolíticas de fronteira e de gestão da mobilidade que têm se tornado uma constante em diversas partes do mundo, continuamos presenciando fluxos permanentes consistentes de circulação de pessoas. $\mathrm{O}$ fato de que os refugiados continuam andando, continuam se movendo, continuam demandando uma resposta dos Estados e dos atores internacionais com relação a seus pleitos é uma forma de resistência ao regime que quer contê-los em seus países de origem, em seus lugares de residência. Essa é uma das principais chaves: a perenidade e a 
permanência dos deslocamentos e a incapacidade desses regimes de controle, dessas políticas xenofóbicas, de conseguirem produzir de fato um freio a esses processos.

Uma segunda dimensão muito importante são as iniciativas de auto-organização e de mobilização social em torno da agenda migratória e do refúgio em diferentes partes do mundo. Muitas delas partem de iniciativas locais, de movimentos de base. Há consequências importantes do ponto de vista da política de acesso a direitos para a inclusão de atores que até então eram marginalizados na agenda política com relação à migração e refúgio, como por exemplo as cidades, as comunidades de bairro. São, em alguma medida, nesses espaços que essas populações vão lutar pela entrada na escola, pelo direito à educação, à saúde, ao permanecimento nesses novos pontos de residência.

Há aí um conjunto bastante heterogêneo e diverso de experiências de mobilização social desses migrantes em termos de pressão política e de coalizações com outros movimentos sociais de cidadãos em situação de precariedade. Por exemplo, no Brasil, fica muito evidente em algumas cidades a articulação de migrantes e refugiados com demandas dos movimentos em prol da habitação, os movimentos sem-teto - que hoje têm uma participação de migrantes e refugiados -, movimentos de direitos de acesso a medicamentos genéricos, a políticas de saúde inclusivas, de pressão pelos regimes de previdência por mais acordos, por regularização documental dessas pessoas e dos lugares onde elas moram.

Algumas iniciativas são mais bem-sucedidas do que outras, mas elas têm mobilizado e energizado uma agenda de respostas e de proposições não só reativas à extrema-direita, mas também propositiva de outras formas - de coabitação, de permanência conjunta, de coexistência pacífica - com essas comunidades.

\section{Que pensadorxs ou escritorxs contemporâneos você acha indispensáveis para começarmos a entender (ou ao menos tentarmos compreender) a situação dos refugiados hoje? Que olhar eles trazem para a questão imigratória?}

Historicamente, o campo de estudos do refúgio e das migrações foi dominado, particularmente no Brasil, pelas áreas do Direito e das Relações Internacionais. A maior parte das contribuições feitas ao campo vinha de estudos, sobretudo, sobre as questões 
jurídicas e políticas desses fluxos. Essa grande contribuição foi responsável por uma certa autonomia do campo de estudo dos refúgios e das migrações. Vemos um conjunto de acadêmicos e pensadores que têm construído uma trajetória cada vez mais transdisciplinar, entendendo a complexidade desse fenômeno e o tamanho do desafio que ele nos coloca, com uma participação muito ativa de diferentes áreas que me parecem muito significativas, como a Antropologia, a Geografia - que historicamente teve um papel muito central, mas que agora tem se aberto para esse olhar mais interdisciplinar -, Letras, Literatura, os estudos da Educação, do Serviço Social, da Psicologia; áreas com um arcabouço importante e que têm muito a contribuir e a dizer, mas que olharam para esse tema de forma muito secundária ou subsidiária aos seus temas centrais. Nas últimas décadas, vimos uma mudança em relação a isso, uma maior participação desses outros campos do conhecimento na literatura sobre refúgio e migração.

Do ponto de vista de autores, no Brasil, temos alguns estudos muito interessantes que tentam olhar de forma mais próxima, descritiva e participativa algumas experiências em comunidades migrantes e refugiadas no país. Há uma bela tese na Geografia, do Instituto de Pesquisa e Planejamento Urbano da UFRJ, o IPPUR, da professora Regina Petrus, sobre a experiência de congolesas no Rio de Janeiro. Recomendo também uma tese da Ângela Facundo, do programa de pós-graduação em Antropologia Social do Museu Nacional, sobre a experiência de colombianos também no Brasil. Um trabalho lindíssimo da antropóloga Sônia Hamid sobre os refugiados palestinos no Brasil. Temos alguns estudos muito interessantes sobre comunidade específicas, com dilemas próprios em relação ao sistema de proteção e às dinâmicas de integração. Está consolidado o tema do refúgio como um tema das ciências humanas e das ciências sociais brasileiras, com uma forte contribuição para a discussão no campo global.

$\mathrm{Na}$ área internacional, fora do Brasil, alguns atores têm olhado para a experiência europeia e lançam luz para questões talvez mais estruturais. Dois autores franceses que me servem como referência permanente são Étienne Balibar, que têm estudos excelentes sobre a relação entre fronteira, cidadania europeia e o tema migratório, e Jacques Rancière, que olha para a experiência desses grupos como um espaço de reflexão sobre os limites da política contemporânea. 
Do ponto de vista de pensar mais o tema da regulamentação internacional e do impacto dessa regulamentação nos processos de acolhimento, integração e reassentamento de populações refugiadas o papel dos Estados e das organizações internacionais, recomendo duas autoras que, apesar de verem esses temas de lugares diferentes, também podem servir como referência para quem quiser se aprofundar no tema de forma importante: a geógrafa Jennifer Hyndman, que tem um estudo sobre a situação dos campos de refugiados a partir de um olhar feminista, e Liisa Malkki, antropóloga americana que tem uma importante contribuição sobre a experiência de refugiados ruandeses. Menciono também um autor mais voltado para o tema da politica propriamente dita, a política dura, entendida como a relação entre Estados e o impacto em processos multilaterais: o britânico Alexander Betts, que tem um conjunto de obras e vem de um centro importante de investigação sobre o tema, o Refugee Studies Centre, da Universidade de Oxford, onde se encontra um grupo de pesquisadores bastante robusto que tem contribuído muito para a literatura acadêmica e policy-oriented no tema da migração forçada no mundo. É um centro que vale a pena acompanhar, porque tem vários especialistas que estão sempre produzindo coisas novas com olhares interessantes a partir de diferentes matizes. 